\title{
SISTEM PENDUKUNG KEPUTUSAN PENERIMAAN BEASISWA KURANG MAMPU DENGAN METODE SIMPLE ADDITIVE WEIGHTING (SAW)
}

\author{
Asep Syaputra \\ Teknik Informatika, Sekolah Tinggi Teknologi Pagaralam \\ Jl. Masik Siagim No.75 Simpang Mbacang Dempo Tengah Pagaralam \\ E-mail : asepsyaputra68@gmail.com
}

\begin{abstract}
In educational institutions, especially schools, there are many scholarships provided for the students, both for the achievers and the underprivileged. Scholarships are provided to ease the tuition fees burden for those who get them. SMA Muhammadiyah Jarai holds scholarship program for the underprivileged students who meet the criteria set by the school, such as parents' occupation, parents' income, number of dependents of their parents, report cards records, and the students' personality. In the process of selecting students for this scholarship program, a system that will speed up the school in selecting students is needed. Thus the Decision Support System with simple additive weighting (SAW) method was chosen. This method is one that can be used to find performance rating of each alternative in all of its attributes. This research is carried out by first defining the criteria of which will be used as a benchmark for solving problems, and normalizing the alternatives in each attribute by assessing past performance ratings then calculating and ranking the weighting of preferences on the alternatives which will find the best alternative( $s$ ) in the selection of scholarship recipients. The result from this research was a system that can help the school in determining students who will receive scholarships based on criteria of and weights determined from SMA Muhammadiyah Jarai.
\end{abstract}

Keywords: Criteria, Simple Additive Weighting (SAW), SPK.

\begin{abstract}
Abstrak
Di berbagai lembaga pendidikan, khususnya sekolah sangat banyak beasiswa yang di tunjukan kepada siswa, baik yang berprestasi maupun yang kurang mampu, beasiswa di tunjukan untuk membantu meringankan beban biaya sekolah bagi siswa yang mendapatkannya, di SMA Muhammadiyah Jarai mengadakan perogram beasiswa kurang mampu untuk siswa dengan memenuhi keriteria-keriteria yang telah ditetapkan oleh sekolah, seperti pekerjaan orang tua, penghasilan orang tua, tanggungan keluarga dari orang tua, nilai raport, keperibadian siswa. Dalam peroses pemilihan siswa untuk beasiswa ini dibutukan sebuah sistem yang akan mempercepat pihak sekolah dalam menyeleksi siswa. Maka dari itu Sistem Pendukung Keputusan dengan metode simpele additive weighting (SAW), metode ini adalah salah satu metode yang dapat digunakan untuk mencari raiting kinerja setiap alternatif di seтиa atribut, riset dilakukan dengan mendefinisikan terlebih dahulu keriteria-keriteria yang akan dijadikan sebagai tolak ukur penyelesaian masalah, dan menormalisasikan alternatif pada setiap atribut cara menilai raiting kinerja lalu menghitung nilai bobot perefrensi pada alternatif dan melakukan perangkingan yang akan menemukan alternatif terbaik dalam pemilihan penerima beasiswa. Hasil dari penelitian ini adalah sebuah sistem yang dapat membantu pihak sekolah dalam menentukan siswa yang akan menerima beasiswa berdasarkan keriteria dan bobot yang ditentukan dari pihak SMA Muhammadiya Jarai. .
\end{abstract}

Kata kunci : Kriteria, Simple Additive Weighting (SAW), SPK.

\section{Pendahuluan}

Pada saat ini informasi berkembang dengan sangat pesat, hal ini terbukti dengan semakin berkembangnya bisnis pelayanan informasi pada bidang pendidikan [1]. Pendidikan dapat dikatakan sebagai sebuah pembelajaran, pengetahuan, keterampilan dan kebiasaan dari sekelompok orang yang diturunkan dari satu generasi ke generasi berikutnya melalui pengajaran, pelatihan atau penelitian, pada pendidikan prasekolah, sampai dengan perguruan tinggi, universitas atau magang, kemudian didalam pendidikan itupun dari Sekolah Dasar (SD) sampai perguruan tinggi akan ada yang namanya pelajar atau mahasiswa berperestasi dan kemudian akan diberikan beasiswa.

Dalam penelitian yogha radithiya mengungkapkan beasiswa dapat dikatakan sebagai pembiayaan yang diberikan oleh pemerintah, perusahaan swasta, kedutaan dan universitas, karena prestasinya dapat diberikan kesempatan untuk meningkatkan kapasitas sumber daya manusia melalui pendidikan, beasiswa ini diberikan kepada orang yang berhak menerima, terutama berdasarkan kompetensi, klasifikasi dan kualitas dari orang yang akan menerima beasiswa [2].

SMA Muhammadiyah Jarai adalah satu-satunya SMA swasta yang ada di Kecamatan Jarai kabupaten lahat yang siap menampung siswa-siswi yang ingin bersekolah yang dipilihnya selain SMA negeri dan SMK negeri, di SMA Muhammadiyah Jarai memiliki satu beasiswa yang di gunakan untuk meringankan beban siswa dalam menempuh masa studi, khususnya dalam masalah biaya yaitu beasiswa kurang mampu, sedangkan di SMA Muhammadiyah Jarai sistem yang digunakan untuk menyeleksi beasiswa masi bersifat manual, karena banyaknya siswa, maka perlu adanya sistem yang secara mandiri dapat menentukan penerimaan beasiswa, metode yang digunakan dalam pembuatan sistem ini adalah metode simpele additive weighting $(S A W)$, Metode $S A W$ banyak digunakan serta 
mudah diaplikasikan karena memiliki algoritma yang tidak terlalu rumit, metode $S A W$ juga disebut dengan metode penjumlahan terbobot, konsep dari metode $S A W$ adalah mencari penjumlahan terbobot dari rating kinerja pada setiap alternatif pada semua atribut, metode $S A W$ membutuhkan proses normalisasi matriks keputusan (X) ke suatu skala yang dapat diperbandingkan dengan 2.6 semua rating alternatif yang ada [3].

Berdasarkan penjelasan diatas, maka penulis mencoba membantu pihak sekolah dalam penentuan siswa yang mendapatkan beasiswa kurang mampu dengan cara membuat sebuah sistem "SISTEM PENDUKUNG KEPUTUSAN BEASISWA KURANG MAMPU MENGGUNAKAN DENGAN METODE SIMPLE ADDITIVE WEIGHTING (SAW) DI SMA MUHAMMADIYA JARAI".

\section{Tinjauan Pustaka}

\subsection{Sistem Pendukung Keputusan}

Michael scoot morton menggungkapkan Sistem Pendukung Keputusan (SPK) dengan istilah management decision system, kemudian sejumlah perusahaan, lembaga penelitian dan perguruan tinggi mulai melakukan penelitain dan membangun sistem pendukung keputusan, Little mendefinisikan sistem pendukungan kepuputusan sebagai suatu informasi berbasis komputer yang menhasilkan berbagai alternatif keputusan untuk membantu manajemen dalam menangani berbagai permasalahan yang terstruktur maupun tidak terstruktur dengan menggunakan data dalam model [4].

\subsection{Tujuan Sistem Pendukung Keputusan} [3]:

Tujuan Sistem Pendukung Keputusan (SPK) yaitu

1. Membantu menejer membuat keputusan untuk memecahkan masalah semi terstruktur.

2. Mendukung penilaian manajer bukan mencoba untuk menggantikannya

3. Meningkatkan ektifitas pengambilan keputusan menejer daripada efisiensinya.

\subsection{Beasiswa Kurang Mampu}

Beasiswa kurang mampu adalah berupa bantuaan yang diberikan kepada mahasiswa ataupun siswa yang mengalami kesulitan membayar biaya pendidikan dan beasiswa ini bertujuan untuk membantu mengurangi beban orang tua dalam hal memenuhi kebutuhan pendidikan anaknya dari kalangan ekonomi lemah [5].

\subsection{Basis Data}

Database atau Basis data adalah sistem terkumputerisasi yang tujuan utamanya adalah memelihara data yang sudah di olah atau informasi dan membuat informasi tersedia atau di butuhkan. Pada intinya baisdata adalah media untuk menyimpan data agar dapat di akses dengan mudah dan cepat [6].

\subsection{Model Data Relasional (RDBMS)}

Model data relasional menggunakan sekumpulan tabel berdimensi dua (yang biasa disebut relasi atau tabel) dengan masing-masing tabel tersusun atas sejumlah baris dan kolom. Kolom dapat didefinisikan sebagai satuan data terkecil dalam sebuah tabel yang mempunyai makna. Baris (sering disebut record) adalah kumpulan kolom yang menyatakan suatu data yang saling terkait. DBMS yang menggunakan model data relasional biasa disebut RDBMS (Relational Database Management System) [7]

\section{Hypertex Markup Langguage (HTML)}

Hypertex Markup Langguage atau HTML adalah bahasa yang digunakan pada dokumen $W E B$ sebagai bahasa untuk pertukaran WEB. Struktur dokumen htmlterdiri dari teg pembuka dan teg penutup. $H T M L$ versi 1.0 dibangun oleh $\mathrm{W} 3 \mathrm{C}$, dan terus mengalami perkembangan. Saat ini $H T M L$ terakhir adalah versi 5.0 [8].

\section{Metodologi Penelitian}

\subsection{Metode Pengumpulan Data}

Teknik pengumpulan data yang digunakan dalam penelitian ini adalah sebagai berikut :

\section{a. Observasi}

Teknik pengumpulan data dengan mengadakan penelitian dan peninjauan langsung ke lokasi objek penelitian dan proses penentuan pemilihan siswa yang mendapat beasiswa di SMA Muhammadiyah jarai.

\section{b. Interview (Wawancara)}

Teknik ini dilakukan dengan mangadakan tanya jawab (wawancara) dengan kepala sekolah SMA Muhammadiyah Jarai mengenai penerimaan beasiswa kurang mampu. Dalam wawancara penulis memperoleh data kriteria yang terdiri dari 5 kriteria dalam penentuan beasiswa di SMA Muhammadiyah Jarai yaitu: (1) pekerjaan orang tua, (2) penghasilan orang tua, (3) jumlah tanggungan orang tua, (4) nilai rapot, (5) keperibadian siswa.

\subsection{Metode Pengembangan Sistem}

Metode pengembangan sistem yang digunakan adalah metode "Waterfall", Model SDLC air terjun (Waterfall) sering juga disebut model sekuensial linier (sequencial linear) atau alur hidup klasik (clasic life cycle), Model air terjun menyediakan pendekatan alur hidup perangkat lunak secara sekuensial atau terurut dimulai dari analisis, desain, pengkodean, pengujian, dan tahap pendukung (support), berikut ini adalah Gambar model Air Terjun [9]:

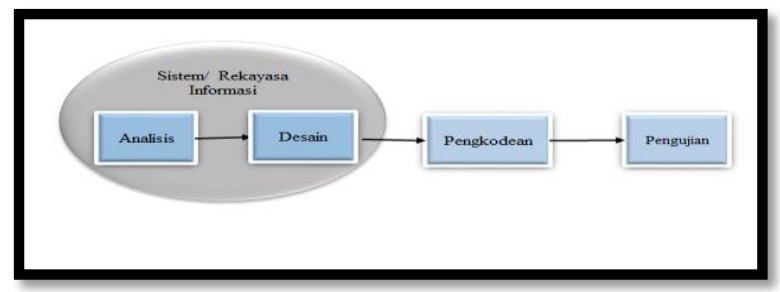

Gambar 1. Metode Waterfall

a. Analisis kebutuhan Prangkat lunak

Proses pengumpulan kebutuhan dilakukan secara intensif untuk menspesifikasikan kebutuhan perangkat lunak agar dapat di pahami perangkat lunak seperti apa yang dibutuhkan oleh user. 
Spesifikasi kebutuhan perangkat lunak pada tahap ini $\mathrm{Wj}$ : nilai bobot kriteria

perlu didukumentasikan [9].

b. Desain

Desain perangkat lunak adalah proses multi langkah

yang fokus pada desain pembuatan perangkat lunak

termasuk struktur data, arsitektur perangkat lunak, representasi antarmuka, dan prosedur pengodean. Tahap ini mentralasi kebutuhan perangkat lunak dari tahap analisis kebutuhan ke representasi desain agar dapat diimplementasikan menjadi program pada tahap selanjutnya. Desain perangkat lunak yang
dihasilkan pada tahp ini perlu didokumentasikan [9].

Pembuatan Kode Program

Desain harus ditranlasikan ke dalam program perangkat lunak. Hasil dari tahap ini adalah program komputer sesuai dengan desain yang telah di buat pada tahap desain [9].

d. Pengujian

Pengujian fokus pada perangkat lunak secara dari segi lojik dan fungsional dan memastikan bahwa semua bagian sudah diuji. Hal ini dilakukan untuk meminimalisir kesalahan (error) dan memastikan keluaran yang di hasilkan sesuai dengan yang diinginkan [9].

\subsection{Metode Simple Additive Weighting (SAW)}

Berdasarkan namanya, metode simple additive weighting dapat di artikan sebagai metode pembobotan sederhana atau penjumlahan terbobot pada penyelesaian masalah dalam sebuah sistem pendukung keputusan, konsep metode ini adalah denga cara raiting kinerja (skala prioritas) pada setiap alternatif di semua atribut. Adapun algoritma penyelesaian masalah dengan Simple Additive Weighting (SAW) [10]

Langkah 1 : mendefinisiskan terlebih dahulu keriteriakeriteria yang akan di jadikan sebagai tolak ukur penyelesaian masalah

Langkah 2 : menormalisasikan setiap alternatif pada setiap atribut dengan cara menilai rating kinerja

Langkah 3 : menghitung nilai bobot preferensi pada setiap alternatif

Langkah 4 : melakukan perengkingan

Adapun rumus yang digunakan pada metode simpele additive waighting yaitu:

a. Menormalisasikan setiap alternatif ( menghitung nilai rating kinerja)

$$
\begin{aligned}
& \text { rij }=\frac{\text { xij }}{\text { Maxi xij }} \\
& \text { jika kriteria } \mathrm{j} \text { adalah atrbut keuntungan (benefit) } \\
& \text { rij }=\frac{\text { Mini xij }}{\text { xij }} \\
& \text { jika kriteria } \mathrm{j} \text { adalah atribut biaya (cost) }
\end{aligned}
$$

b. Menghitung bobot pereferensi pada setiap alternate

$$
\mathrm{Vi}=\sum_{\mathbf{j}=1}^{\mathrm{n}} \mathrm{Wj} \text { rij }
$$

Keterangan :

$\mathrm{Vi}$ : nilai bobot preferensi dari setiap alternatif

Jurnal Ilmiah Binary STMIK Bina Nusantara Jaya

Vol. 01 No. 02 Tahun 2019, ISSN : 2657-2117
Rij : nilai raiting kerja

\subsection{Analisis Kebutuhan Sistem}

Dalam peroses penyeleksisan calon penerima beasiswa kurang mampu di SMA Muhammadiyah Jarai, data yang dibutukan adalah kriteria yang dijadikan ebagai acuan dalam pengambilan keputusan, alternatif yaitu siswa, rating kecocokan pada setiap alternatif pada setiap kriteria, dan bobot kepentingan. Adapun output yang akan dihasilkan dari penelitian ini adalah sebuah alternatif yang memiliki nilai tertinggi dibandingkan dengan alternatif nilai yang lain. Hasil outputnya diambil dari urutan alternatif tertinggi ke alternatif yang terendah. Alternatif yang dimaksud disini adalah seluruh siswa calon penerima beasiswa kurang mampu di SMA

\subsection{Analisis Bobot Nilai Kriteria}

1. Kriteria Pekerjaan Orangtua

Tabel 1. Pekerjaan Orangtua

\begin{tabular}{cc}
\hline C1 & Bobot $(\mathbf{W})$ \\
\hline PNS & 20 \\
\hline Karyawan Swasta & 40 \\
\hline Pedagang & 60 \\
\hline Petani & 80 \\
\hline Tidak Pekerja & 100
\end{tabular}

2. Kriteria Penghasilan Orang Tua

Penghasilan orangtua di dapat dari gaji atau pendapatan orangtua tiap bulannya yang bisa di lihat di tabel berikut:

Tabel 2. Penghasilan Orangtua

$\left.\begin{array}{cc}\hline \text { C2 } & \text { Bobot(W) } \\ \hline>\operatorname{Rp~2.000.000~} & 20 \\ \hline>\operatorname{Rp~} 1.500 .000-<=\mathrm{RP} & 40 \\ 2.000 .000 & 60 \\ \hline>\operatorname{Rp~} 1.000 .000-<=\mathrm{Rp} \\ 1.500 .000\end{array}\right)$

3. Kriteria Tanggungan Orangtua

Jumlah tanggungan atau jumlah saudara dalam keluarga data ini di dapat dari guru Bimbingan Konseling (BK) yang terdapat dalam buku data pribadi murid.

Tabel 3. Tanggungan Orangtua

\begin{tabular}{cc}
\hline C3 & Bobot(W) \\
\hline $1-2$ anak & 20 \\
\hline 3 anak & 40 \\
\hline 4 anak & 60 \\
\hline 5 anak & 80 \\
\hline >=5 anak & 100 \\
\hline
\end{tabular}


4. Kriteria Nilai Raport

Nilai raport siswa di ambil dari jumlah seluruh aspek nilai mata pelajaran yang hasil jumlah nya di lihat di dalam buku data pribadi murid SMA Muhammadiya jarai sesuai dengan tahun pelajaran yang sudah di tempuh.

\begin{tabular}{cc}
\multicolumn{2}{c}{ Tabel 4. Nilai Raport } \\
\hline C5 & $\operatorname{Bobot}(\mathbf{W})$ \\
\hline $45,99-54,99$ & 20 \\
\hline $55,99-64,99$ & 40 \\
\hline $65,99-74,99$ & 60 \\
\hline $75,99-84,99$ & 80 \\
\hline $85,99-100$ & 100 \\
\hline
\end{tabular}

5. Kriteria Data Kepribadian

Data kepribadian ini di ambil dari guru BK yang di nilai dari kepatutannya, kejujuran, rasa tanggung jawab, emosi, hubungan dengan teman baik di sekolah maupun di luar sekolah, hubungan dengan guru, dari semua aspek itu di nilai bagaimana prilaku siswa yang tercantum di dalam raport siswa.

Tabel 5. Nilai Kepribadian

\begin{tabular}{cc}
\hline C6 & Bobot $(\mathbf{W})$ \\
\hline Jelek & 20 \\
\hline Cukup Baik & 40 \\
\hline Cukup & 60 \\
\hline Baik & 80 \\
\hline Sangat Baik & 100 \\
\hline
\end{tabular}

\subsection{Perancangan Sistem}

\section{Use Case Diagram}

Berikut ini adalah Use Case Diagram pada SMA Muhammadiya Jarai.

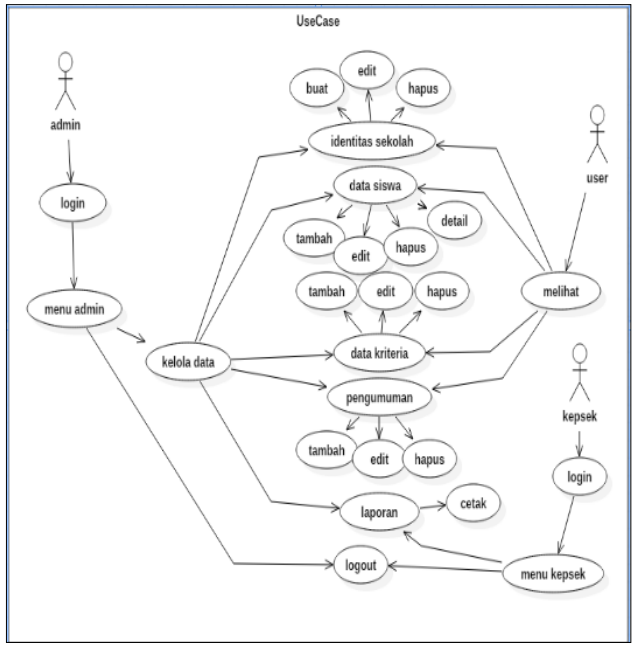

Gambar 2. Use Case Diagram pada SMA Muhammadiya Jarai

2. Class Diagram

Berikut ini adalah Class Diagram yang dibangun

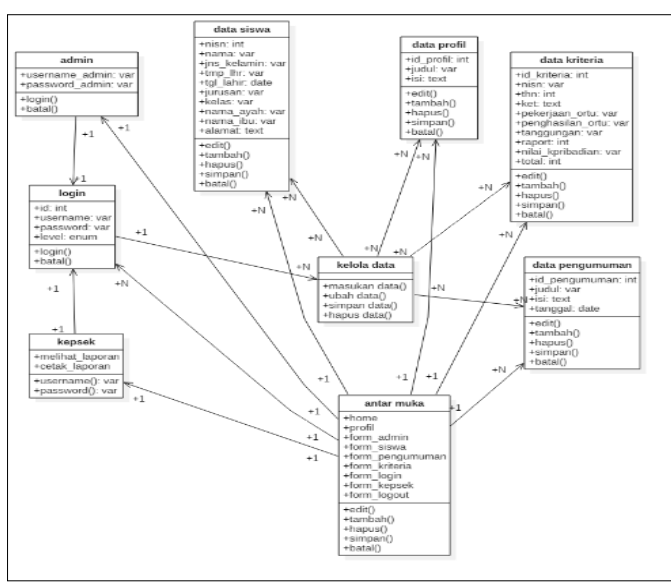

Gambar 3. Class Diagram

\section{Hasil dan Pembahasan}

Adapun untuk contoh kasusnya dalam pemecahan permasalahan dengan menggunakan metode $S A W$ diantaranya sebagai berikut: Menentukan jenis-jenis kriteria dan alternatif, alternatif dalam penelitian ini adalah di sekolah mencari siapa siswa yang berhak menerima bantuan siswa kurang mampu. penulis akan menggunakan 3 alternatif dalam contoh perhitungan metode $S A W$ ada alternatif 1 (A1), altrenatif 2 (A2), dan alternatif 3 (A3).

Tabel 6. Rating Kecocokan dari Data Awal

\begin{tabular}{cccccc}
\hline $\begin{array}{l}\text { Altern } \\
\text { atif }\end{array}$ & $\begin{array}{l}\text { Pekerj } \\
\text { aan } \\
\text { orang } \\
\text { tua }\end{array}$ & $\begin{array}{l}\text { Jumlah } \\
\text { penghasila } \\
\text { tua orang }\end{array}$ & $\begin{array}{l}\text { Jumlah } \\
\text { tanggun } \\
\text { gan } \\
\text { orang } \\
\text { tua }\end{array}$ & $\begin{array}{l}\text { Nilai } \\
\text { rapot }\end{array}$ & $\begin{array}{c}\text { keperi } \\
\text { badian }\end{array}$ \\
\hline A1 & Petani & 800.000 & 2 & $\begin{array}{c}64,9 \\
9\end{array}$ & $\begin{array}{c}\text { Sangat } \\
\text { baik }\end{array}$ \\
\hline A2 & Pns & 1.200 .000 & 4 & $\begin{array}{c}73,5 \\
5\end{array}$ & cukup \\
\hline A3 & $\begin{array}{c}\text { Pedaga } \\
\text { ng }\end{array}$ & 500.000 & 5 & $\begin{array}{c}84,7 \\
7\end{array}$ & baik \\
\hline
\end{tabular}

1. Menentukan bobot preferensi atau tingkat kepentingan $(W)$ dari setiap kriteria.

Tabel 7. Rating Kecocokan dari Data Awal

\begin{tabular}{lccccc}
\hline Kriteria & C1 & C2 & C3 & C4 & C5 \\
\hline $\begin{array}{l}\text { Rating } \\
\text { kepentingan }\end{array}$ & 4 & 3 & 1 & 5 & 3 \\
\hline
\end{tabular}

2. Membuat matrik keputusan

$\mathrm{X} \quad \mathrm{X} 20602060100$


3. Melakukan noramalisasi matrik keputusan X dengan 5. Hasil akhir nilai preferensi (vi) diperoleh dari cara menghitung nilai rating kinerja ternormalisasi (Rij) dari alternatif (Ai) pada kriteria $(\mathrm{Cj})$.

$$
\mathrm{R} 11=\frac{80}{\operatorname{Max}(80,20,60)}=\frac{80}{80}=1
$$$$
\mathrm{R} 12=\frac{60}{\operatorname{Max}(60,20,100)}=\frac{60}{100}=0.6
$$$$
\mathrm{R} 13=\frac{20}{\operatorname{Max}(20,60,100)}=\frac{20}{100}=0.2
$$$$
\mathrm{R} 14=\frac{60}{\operatorname{Max}(60,80,100)}=\frac{60}{100}=0.6
$$$$
\mathrm{R} 15=\frac{100}{\operatorname{Max}(100,100,80)}=\frac{100}{100}=1
$$$$
\mathrm{R} 21=\frac{20}{\operatorname{Max}(80,20,60)}=\frac{20}{80}=0.25
$$$$
\mathrm{R} 22=\frac{20}{\operatorname{Max}(60,20,100)}=\frac{20}{100}=0.2
$$$$
\mathrm{R} 23=\frac{60}{\operatorname{Max}(20,60,100)}=\frac{60}{100}=0.6
$$$$
\mathrm{R} 24=\frac{80}{\operatorname{Max}(60,80,100)}=\frac{80}{100}=0.8
$$$$
\mathrm{R} 25=\frac{100}{\operatorname{Max}(100,100,80)}=\frac{100}{100}=1
$$$$
\mathrm{R} 21=\frac{60}{\operatorname{Max}(80,20,60)}=\frac{60}{80}=0,75
$$$$
\mathrm{R} 22=\frac{100}{\operatorname{Max}(60,20,100)}=\frac{100}{100}=1
$$$$
\mathrm{R} 23=\frac{100}{\operatorname{Max}(20,60,100)}=\frac{100}{100}=1
$$$$
\mathrm{R} 24=\frac{100}{\operatorname{Max}(60,80,100)}=\frac{100}{100}=1
$$$$
\mathrm{R} 25=\frac{80}{\operatorname{Max}(100,100,80)}=\frac{80}{100}=0.8
$$

4. Hasil dari nilai Raiting kinerja ternormalisasi (Rji) membentuk matrik ternnormalisasi (R).

$$
\mathrm{R}=\left(\begin{array}{cccccc}
1 & 0.6 & 0.2 & 0.6 & 1 \\
0.25 & 0.2 & 0.6 & 0.8 & 1 \\
0,75 & 1 & 1 & 1 & 0.8
\end{array}\right)
$$
perkalian dan penjumlahan elemen baris matrik ternormalisasi $(\mathrm{R})$ dengan bobot prefrensi (w) yang bersesuaian elemen kolom matrik (w).

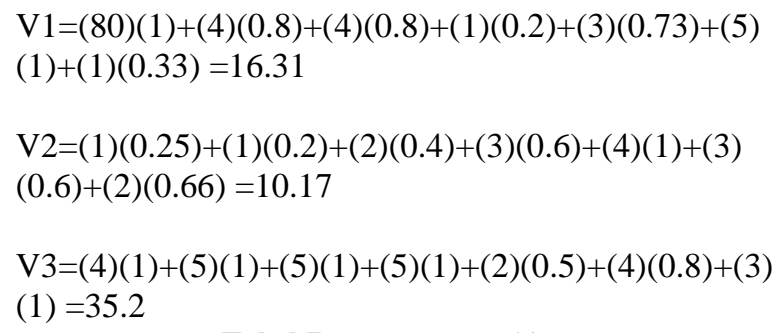

Tabel 7. Peroses Prengkingan

\begin{tabular}{cccc}
\hline Rangking & Vi & Nama & Nilai \\
\hline 1 & V1 & $\begin{array}{c}\text { Hendi } \\
\text { setiawan }\end{array}$ & 16.31 \\
\hline 2 & V2 & Dendi arol & 10.17 \\
\hline 3 & V3 & $\begin{array}{c}\text { Septi } \\
\text { anggraini }\end{array}$ & 35.2 \\
\hline
\end{tabular}

Nilai terbesar ada pada V1 yang merupakan alternatif terpilih untuk alternatif terbaik sebagai siswa yang menerima beasiswa kurang mampu.

\subsection{Implementasi Sistem}

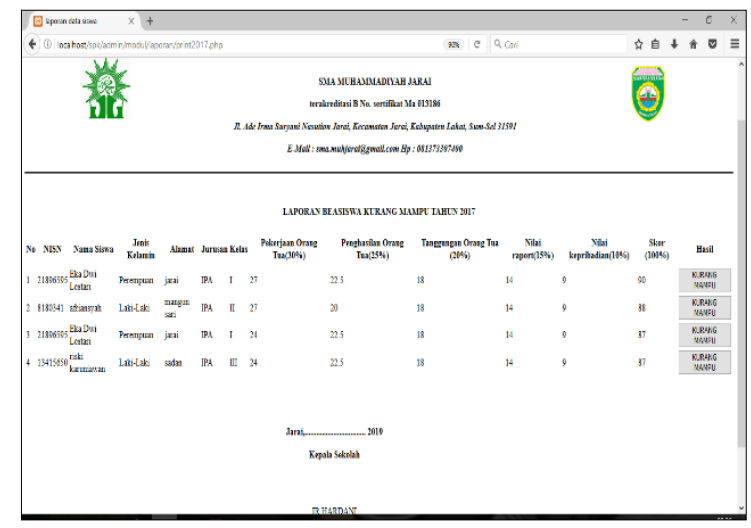

Gambar 4. Halaman hasil perhitungan

Pada gambar 4 diperoleh hasil perhitungan dengan menggunakan sistem yang telah dibangun. Dimana penerimaan beasiswa kurang mampu untuk siswa SMA Muhammadiya Jarai ditentukan dengan nilai 16.31.

\section{Kesimpulan dan Saran 5.1. Kesimpulan}

Dengan adanya pembuatan sistem pendukung keputusan penerimaan beasiswa kurang mampu dengan metode Simple Additive Weighiting (SAW) di SMA Muhammadiyah Jarai. Menggunakan macromedia dreamweaper, $P H P$, dan $M y S Q L$ sebagai databasenya, memungkinkan diperoleh sistem yang dinamis dan mudah di update kapan saja. Dari analisis yang telah dilakukan pada SMA Muhammadiyah Jarai maka penulis membuat kesimpulan sebagai berikut:

Penelitian ini menghasilkan sistem pendukung keputusan penerimaan beasiswa kurang mampu dengan 
metode Simpele Aditve Weighting (SAW) di SMA Muhammadiyah Jarai

1. Di buat untuk memudakan pemilihan beasiswa kurang mampu di SMA Muhammadiyah Jarai

2. Bagian terdiri atas simpulan dan saran atas penelitian hasil penelitian.

\subsection{Saran}

Saran yang dapat diberikan dan untuk menunjang keberhasilan Sistem Pendukung Keputusan Penerimaan Beasiswa Kurang Mampu Dengan Metode Simple Additive Weighiting (SAW) Di SMA Muhammadiyah Jarai yaitu:

1. Sistem Pendukung Keputusan Penerimaan Beasiswa Kurang Mampu Dengan Metode Simple Additive Weighiting $(S A W)$ Di SMA Muhammadiyah Jarai ini lebih interaktif maka

2. Untuk penelitian selanjutnya pengembang Sistem Pendukung Keputusan Penerimaan Beasiswa Kurang Mampu Dengan Metode Simple Additive Weighiting $(S A W)$ Di SMA Muhammadiyah Jarai perlu menambakan persyaratan kriteria lebih banyak lagi

3. Tampilan Website dapat dibuat lebih menarik dan dinamis lagi

\section{Daftar Rujukan}

[1] Maharsi, Sri pengaruh perkembangan teknologi informasi terhadap bidang akutansi manajemen, vol. 2, No.2, 2000.

[2] Yogha Radhitya1, F. N. Rancang Bangun Sistem Pendukung Keputusan Penentuan Penerima Beasiswa. Journal Speed - Sentra Penelitian Engineering Dan Edukasi, vol. 8, No 2, 2016.

[3] Jamal Hadi Susanto, Permanan Ginting Munthe, Mba. penerapan assessment center untuk pemilihan. 2014

[4] defit, d. n. (2017). multi criteria decision making (mcdm) pada sistem pendukung keputusan, 23-27.

[5] Umum, P. (2004:1).

[6] Rosa A.S M.Shalahuddin .(2018). Rekayasa Perangkat Lunak. Dalam R. A. M.Shalahuddin, Rekayasa Perangkat Lunak. Bandung: Informatika Bandung, 43-44.

[7] Abdul Kadir. (2014:34). Pengenalan Sistem Informasi Edisi Revisi. Dalam A. Kadir, Pengenalan Sistem Informasi Edisi Revisi.Yogyakarta: Andi.

[8] Alexander F.K. Sibero. 2014. Web Programming Power Pack. Penerbit Mediakom. Yogyakarta.

[9] Rosa A.S M.Shalahuddin .(2018). Rekayasa Perangkat Lunak. Dalam R. A. M.Shalahuddin, Rekayasa Perangkat Lunak. Bandung: Informatika Bandung, 23-30.

[10] Nofriansyah, Diky. (2017) Multi Criteria Decision Making (Mcdm) Pada Sistem Pendukung Keputusan. Yogyakarta, 33-37. 